\title{
Comparison between direct assay and popular equations for Low Density Lipoprotein-cholesterol estimation in Nepalese population
}

\author{
Saroj Thapa ${ }^{1}$, Pratikshya Gyawali ${ }^{1}$, Rajendra Dev Bhatta ${ }^{1}$, Prabodh Risal ${ }^{1}$ \\ ${ }^{l}$ Department of Clinical Biochemistry, Kathmandu University School of Medical Sciences, Dhulikhel, Nepal.
}

\section{Keywords:}

Friedewald equation; Low density lipoprotein cholesterol;

Triglyceride;

\section{Correspondence:}

Dr. Saroj Thapa, MBBS, MD Lecturer

Department of Clinical Biochemistry

Kathmandu University School of Medical Sciences

Dhulikhel, Nepal

ORCID ID: 0000-0003-1234-644X

Email:drsarojthapa@gmail.com

Received : January $8^{\text {th }} 2020 ;$ Accepted : March $6^{\text {th }} 2020$

Citation: Thapa S, Gyawali P, Bhatta RD, Risal P. Comparison between direct assay and popular equations for Low Density Lipoprotein-cholesterol estimation in Nepalese population. J Pathol Nep 2020;10:1618-24 DOI 10.3126/jpn.v10i1.27163

Copyright: This is an open-access article distributed under the terms of the Creative Commons Attribution 4.0 International License, which permits unrestricted use, distribution, and reproduction in any medium, provided the original author and source are credited.

\begin{abstract}
Background: The aim of this study was to compare LDL-C estimations using various equations with directly measured LDL-C and to find the most accurate and reliable equation for measuring serum LDL-C at different triglycerides level.

Materials and Methods: In this study, we performed a retrospective analysis on the database of our Laboratory Information System to retrieve results of lipid profile in patients visiting Dhulikhel Hospital during the period of 6 months. A total of 1420 participants were classified into three groups according to triglyceride (TG) concentrations as follows: $<150,150-199$ and $>199 \mathrm{mg} / \mathrm{dL}$. LDL-C was calculated sing the Friedewald, Chen, Vujovic, Hattori, Anandaraja and modified Friedewald equations and compared with directly measured LDL-C concentration (enzymatic method on Biosystems, BA-400).

Results: In most of the instances, calculated LDL-C value was higher than the directly measured LDL-C values with negative mean difference with the exception of Hattori equation. The intraclass correlation coefficient (ICC) between the estimated and directly-measured LDL-C was higher with the Friedewald equation (ICC $=0.917 ; 95 \%$ CI: 0.904-0.927) for all serum TG ranges compared with other equations. The reliability of all the equations was good with ICC being above 0.75 while that of the Friedewald equation was excellent in all the TG groups with ICC being above 0.9. Hattori equation was better in estimating LDL-C at normal TG range ( $\mathrm{ICC}=0.927 ; 95 \% \mathrm{CI}: 0.917-0.937)$ and borderline high $\mathrm{TG}(\mathrm{ICC}=0.933$; 95\% CI: 0.908-0.951).
\end{abstract}

Conclusion: Calculated LDL-C using appropriate equations can be an alternative cost-effective tool to measure LDL-C when the direct measurement cannot be afforded.

\section{INTRODUCTION}

Dyslipidemia is one of the major modifiable risk factor for cardiovascular disease (CVD). Among the various component of traditional lipid profile, Low density Lipoprotein Cholesterol (LDL-C) is considered as the most appropriate factor for patient classification in risk management of CVD. Elevated LDL-C is a well-known atherogenic risk factor with high predictive value for coronary heart disease. ${ }^{1}$

The National Cholesterol Education Program (NCEP) Adult Treatment Panel III (ATP III) recommends a goal of maintaining serum LDL-C concentration $<100 \mathrm{mg} / \mathrm{dl}$ 
as optimal. It is also the basis for initiating appropriate treatment and patient's risk stratification. ${ }^{2}$ This highlights the importance of comprehensive understanding of the need for accurate and precise LDL-C estimation. Various methods are available for measuring serum LDL-C concentration. The accepted gold standard or reference method for LDL-C estimation is ultracentrifugation followed by beta quantification. Beta quantification is not suited for routine use, as it requires ultracentrifugation, large volume of samples, expensive instruments and is time consuming. ${ }^{3}$ Direct homogeneous assays for measurement of LDL-C have been developed and have shown reasonable accuracy and precision when compared with the reference method. Measurement of LDL-C by direct method is expensive compared with other traditional lipid profile parameters.

In routine practice, most clinical laboratories in Nepal report LDL-C by indirect method using different equations. Several equations have been developed to estimate LDL-C. . $^{4-9}$ It is very important to use suitable laboratory methods and achieve accurate results. It is necessary to know about the agreement of results obtained by these different methods. However, studies done in many parts of the world to compare the agreement of different equations with direct LDL-C estimation have shown conflicting results. ${ }^{10-16}$ There is no any study published till date to guide the laboratory personals about the best equation at different triglyceride level in our setting. Thus the aim of this study was to assess the performance of the common equations and compare these formulas with direct measurement method and to find the most accurate and reliable equation for measuring serum LDL-C at different triglycerides level.

\section{MATERIAL AND METHODS}

In this study, we performed a retrospective analysis on the database of our Laboratory Information System (LIS) to retrieve results of lipid profile in patients visiting Dhulikhel Hospital during the period of 6 months (1st January 2019 to 30th June 2019). The lipid profile test included triacylglycerol (TG), total cholesterol (TC), High density lipoprotein cholesterol (HDL-C), and Low density lipoprotein cholesterol (LDL-C). A total of 1420 participants were classified into three groups according to triglyceride concentrations as follows: $<150 \mathrm{mg} / \mathrm{dl}, 150$ $199 \mathrm{mg} / \mathrm{dl}$, and $>199 \mathrm{mg} / \mathrm{dl}$. The basis of classification into three different TG groups was per according to ATP III levels of normal TG, borderline high TG and high $\mathrm{TG}^{2} \mathrm{We}$ excluded all the cases with very high TG i.e $>500 \mathrm{mg} / \mathrm{dl}$ as almost all studies done till date have discouraged the use of equations to calculate LDL-C above this range. ${ }^{3,4,12,16}$ The laboratory method for measurement of LDL-C, HDL-C, TC, and TG was enzymatic spectrophotometric method using commercial kits by BioSystems (BA-400, BioSystems S.A. Spain). In addition to direct measurement, LDL-C was calculated according to the following equations:
1) Friedwald Equation ${ }^{4}: \mathrm{LDL}=\mathrm{TC}-\mathrm{HDL}-(\mathrm{TG} / 5)$

2) Anandraja Equation $5: \mathrm{LDL}=(0.9 \mathrm{TC})-(0.9 \mathrm{TG} / 5)-28$

3) Chen Equation ${ }^{6}: \mathrm{LDL}=(\mathrm{TC}-\mathrm{HDL}) \times 0.9-(\mathrm{TG} \times 0.1)$

4) Hattori Equation ${ }^{8}$ : LDL-C $=(0.94 \times \mathrm{TC})-(0.94 \times$ HDL-C $)$ $(0.19 \times \mathrm{TG})$

5) Vujovic Equation': LDL-C=TC-HDL-C-(TG/6.58)

6) Modified Friedwald Equation ${ }^{17}$ :LDL-C $=$ TC $-(T G / 6+$ HDLC)

Data was entered in MS Excel 2010, and analyzed with Statistical Package for Social Sciences (SPSS Inc., Chicago, USA) version 21.0. Data was classified according to the TG level into three groups as described previously. The performance of all estimated formulas was compared at different concentrations of TG. Continuous variables were described as means with standard deviations or as a median with an interquartile range depending on their distribution. Data were compared using an independent t-test, one way ANOVA and Wilcoxon rank sum test. Correlations between LDL-C by estimated formulas and by direct measurement was calculated using the Pearson's correlation. The intraclass correlation coefficient (ICC) analysis was performed in order to evaluate the reliability across two measurements. ICC estimates and their 95\% confident interval (CI) were calculated. Bland-Altman plots were used to evaluate the agreement and absolute difference between the formulas and the directly measured LDL-C, respectively. Statistical significance was defined as a two-sided p-value of less than 0.05 .

\section{RESULTS}

The total number of participants was 1420 with mean age of $48.4 \pm 14.7$ years. Among the total participants 804 (56.6\%) were male and $616(43.4 \%)$ were female. The mean serum total cholesterol, HDL-C and direct LDL-C concentration was $173.5 \pm 40.7,41.8 \pm 11.4$ and $95.9 \pm 32 \mathrm{mg} / \mathrm{dl}$ respectively. The concentration of triacylglycerol (TG) ranged from $33 \mathrm{mg} / \mathrm{dl}$ to $498 \mathrm{mg} / \mathrm{dl}$ with median of $141(95,211) \mathrm{mg} /$ dl. Among the total participants, 766 (53.9\%) had normal TG (TG $<150 \mathrm{mg} / \mathrm{dl}), 254$ (17.9\%) had borderline high TG $(\mathrm{TG}=150-199 \mathrm{mg} / \mathrm{dl})$ and $400(28.2 \%)$ had high TG (TG $\geq 200 \mathrm{mg} / \mathrm{dl}$ ). The distribution of age and lipid profile including calculated LDL-C values in both genders is shown in Table 1. The mean serum HDL-C was significantly higher in females whereas the mean serum TG was significantly higher in male patients.

The mean concentration along with standard deviations of different lipid profile parameters including direct LDL and calculated LDL across different triacylglycerol concentration 
Table 1: Age and lipid profile differences according to gender

\begin{tabular}{l|ccc}
\hline & Female & Male & p-value \\
\hline Age & $48.3 \pm 14.8$ & $48.4 \pm 14.6$ & 0.94 \\
\hline Total cholesterol & $173.5 \pm 39$ & $173.6 \pm 42$ & 0.95 \\
\hline HDL-C & $44.3 \pm 11.5$ & $39.9 \pm 11$ & $<0.001$ \\
\hline Triacylglycerol & $134(93,193)$ & $156(101,236)$ & $<0.001$ \\
\hline Direct LDL-C & $95.8 \pm 31.4$ & $96.1 \pm 32.45$ & 0.87 \\
\hline Friedewald LDL & $98.6 \pm 34$ & $98.6 \pm 35$ & 0.98 \\
\hline Anandaraja LDL & $100.7 \pm 33.1$ & $96.6 \pm 33.5$ & 0.02 \\
\hline Chen LDL & $101 \pm 31.4$ & $102.8 \pm 33.3$ & 0.3 \\
\hline Hattori LDL & $92.4 \pm 31.9$ & $92.3 \pm 32.9$ & 0.96 \\
\hline Vujovic LDL & $106 \pm 34.3$ & $107 \pm 35.8$ & 0.5 \\
\hline Modified Friedewald LDL & $103.7 \pm 34.1$ & $104.4 \pm 35.5$ & 0.7 \\
\hline
\end{tabular}

Data expressed as mean $\pm S D$, Median (25th percentile, 75th percentile)

Table 2: Lipid profile differences according to different TG concentration

\begin{tabular}{|c|c|c|c|c|}
\hline & TG $<150 \mathrm{mg} / \mathrm{dl}$ & TG $150-199 \mathrm{mg} / \mathrm{dl}$ & TG>199 mg/dl & p-value \\
\hline HDL-C & $45 \pm 11$ & $40 \pm 11$ & $36 \pm 11$ & $<0.001$ \\
\hline Total Cholesterol & $159 \pm 35$ & $182 \pm 40$ & $195 \pm 40$ & $<0.001$ \\
\hline Direct LDL & $89 \pm 29$ & $104 \pm 33$ & $103 \pm 34$ & $<0.001$ \\
\hline Friedewald LDL & $94.1 \pm 31.6$ & $107.6 \pm 35.8$ & $101.8 \pm 37.8$ & $<0.001$ \\
\hline Anandaraja LDL & $97.4 \pm 30.6$ & $105.1 \pm 35.5$ & $96.1 \pm 36.6$ & 0.001 \\
\hline Chen LDL & $92.6 \pm 29$ & $110.6 \pm 32.3$ & $114.6 \pm 33.4$ & $<0.001$ \\
\hline Hattori LDL & $88.2 \pm 29.7$ & $100.8 \pm 33.6$ & $95.1 \pm 35.5$ & $<0.001$ \\
\hline Vujovic LDL & $98.9 \pm 31.9$ & $115.8 \pm 35.8$ & $115.6 \pm 37.3$ & $<0.001$ \\
\hline Modified Friedewald LDL & $97.4 \pm 31.8$ & $113.3 \pm 35.8$ & $111.4 \pm 37.4$ & $<0.001$ \\
\hline
\end{tabular}

is shown in Table 2. Mean HDL-C concentration was lower in borderline high and high TG groups compared to normal TG group.

The comparison between estimated LDL-C using six formulas to directly measured LDL-C according to the TG concentration is shown in table 3 . The mean value of LDL-C along with the mean difference in all groups classified according to TG level is also shown in Table 3. In most of the instances, calculated LDL-C value was higher than the directly measured LDL-C values with negative mean difference with the exception of Hattori equation. The ICC between the estimated and directly-measured LDL-C was significantly higher with the Friedewald equation ( $\mathrm{ICC}=0.917$; 95\% CI: 0.904-0.927) for all serum TG ranges compared with other equations as shown in table 3. Except for the calculated LDL-C using Hattori equation ( $p$ value $=0.923$ ), there was significant difference between mean of directly measured and all other calculated LDL-C. The reliability of all the equations was good with ICC being above 0.75 while that of the Friedewald equation was excellent in all the TG groups with ICC being above 0.9 .

To find the agreement between the direct and calculated LDL methods, Bland-Altman Plot was prepared [figure
1].The mean bias for the Friedewald formula was -2.66 $\pm 13.37 \mathrm{mg} / \mathrm{dl},-2.44 \pm 17.66 \mathrm{mg} / \mathrm{dl}$ for the Anandaraja formula, $-6.04 \pm 12.38 \mathrm{mg} / \mathrm{dl}$ for the Chen formula, 3.58 $\pm 12.79 \mathrm{mg} / \mathrm{dl}$ for the Hattori formula, $-10.61 \pm 12.89 \mathrm{mg} /$ $\mathrm{dl}$ for the Vujovic formula and $-8.18 \pm 12.87 \mathrm{mg} / \mathrm{dl}$ for the modified Friedewald formula.

\section{DISCUSSION}

LDL-C is the primary target for diagnosis and treatment of patients with hyperlipidemia. ${ }^{2,18}$ It has important implications in cardiovascular risk stratification and has been focused on therapeutic decision-making. ${ }^{19}$ It is essential to accurately estimate LDL-C concentration, inability of which can adversely influence therapy and outcomes in patients. Currently, there are several methods for the estimation of LDL-C. In the present study we compared calculated LDL-C using six different formulas with directly measured LDL-C across different triglyceride concentration in Nepalese population. Overall, the correlation between estimated LDL-C and measured LDL-C was good. Overall, the Friedewald formula showed the best performance for estimating LDL-C (ICC $=0.917$; 95\% CI: 0.904-0.927) with the mean difference of $-2.44 \mathrm{mg} / \mathrm{dl}$ compared to the directlymeasured LDL-C. Similar to our study, previous studies 
Table 3: Comparison of estimated formulas to directly-measured LDL-C according to serum TG concentration

\begin{tabular}{|c|c|c|c|c|}
\hline TG level & LDL-C measurement & Mean \pm SD $(m g / d L)$ & Mean difference & $\begin{array}{l}\text { ICC (confidence } \\
\text { interval) }\end{array}$ \\
\hline \multirow{7}{*}{ Overall } & Directly-measured & $95.9 \pm 32$ & NA & NA \\
\hline & Friedewald & $98.6 \pm 34.5$ & -2.66 & $0.917(0.904-0.927)$ \\
\hline & Anandaraja & $98.4 \pm 33.4$ & -2.44 & $0.852(0.836-0.867)$ \\
\hline & Chen & $102 \pm 32.5$ & -6.04 & $0.910(0.844-0.943)$ \\
\hline & Hattori & $92.4 \pm 32.5$ & 3.58 & $0.916(0.895-0.931)$ \\
\hline & Vujovic & $106.6 \pm 35.1$ & -10.61 & $0.883(0.597-0.947)$ \\
\hline & Modified Friedewald & $104.1 \pm 34.9$ & -8.18 & $0.899(0.763-0.946)$ \\
\hline \multirow{7}{*}{ Normal TG } & Directly-measured & $89 \pm 29$ & NA & NA \\
\hline & Friedewald & $94.1 \pm 31.6$ & -4.66 & $0.914(0.872-0.939)$ \\
\hline & Anandaraja & $97.4 \pm 30.6$ & -8.03 & $0.845(0.715-0.905)$ \\
\hline & Chen & $88.2 \pm 29.7$ & -3.21 & $0.925(0.903-0.941)$ \\
\hline & Hattori & $88.2 \pm 29.7$ & 1.17 & $0.927(0.917-0.937)$ \\
\hline & Vujovic & $98.9 \pm 31.9$ & -9.44 & $0.883(0.613-0.947)$ \\
\hline & Modified Friedewald & $97.4 \pm 31.8$ & -7.98 & $0.895(0.727-0.946)$ \\
\hline \multirow{7}{*}{ Borderline High TG } & Directly-measured & $104 \pm 33$ & NA & NA \\
\hline & Friedewald & $107.6 \pm 35.8$ & -3.21 & $0.932(0.910-0.949)$ \\
\hline & Anandaraja & $105.1 \pm 35.5$ & -0.71 & $0.885(0.855-0.909)$ \\
\hline & Chen & $110.6 \pm 32.3$ & -6.58 & $0.921(0.841-0.954)$ \\
\hline & Hattori & $100.8 \pm 33.6$ & 3.58 & $0.933(0.908-0.951)$ \\
\hline & Vujovic & $115.8 \pm 35.8$ & -11.48 & $0.887(0.514-0.955)$ \\
\hline & Modified Friedewald & $113.3 \pm 35.8$ & -8.95 & $0.906(0.722-0.955)$ \\
\hline \multirow{7}{*}{ High TG } & Directly-measured & $103 \pm 34$ & NA & NA \\
\hline & Friedewald & $101.8 \pm 37.8$ & 1.50 & $0.903(0.883-0.920)$ \\
\hline & Anandaraja & $96.1 \pm 36.6$ & 7.16 & $0.839(0.771-0.883)$ \\
\hline & Chen & $114.6 \pm 33.4$ & -11.32 & $0.866(0.563-0.940)$ \\
\hline & Hattori & $95.1 \pm 35.5$ & 8.18 & $0.883(0.772-0.930)$ \\
\hline & Vujovic & $115.6 \pm 37.3$ & -12.30 & $0.861(0.545-0.937)$ \\
\hline & Modified Friedewald & $111.4 \pm 37.4$ & -8.08 & $0.888(0.786-0.933)$ \\
\hline
\end{tabular}

The mean difference (directly-measured $L D L-C$ - estimated $L D L-C$ ) represents the estimation of bias between the two observations. $L D L-C$ : low-density lipoprotein cholesterol, TG: triglycerides, SD: standard deviation, ICC: intraclass correlation coefficient, NA: not applicable

have also reported that Friedewald calculation demonstrates better agreement with directly measured LDL-C. ${ }^{12,}{ }^{20}$ The performance of Friedewald equation was fairly constant in all the TG groups. Hattori equation was better in estimating LDL-C at normal TG group (ICC $=0.927 ; 95 \%$ CI: 0.917 0.937 ) and borderline high TG group (ICC $=0.933 ; 95 \% \mathrm{CI}$ : 0.908-0.951). Our finding was similar to the study done to compare the accuracy between four formulae in calculating LDL-C, which reported that the Hattori formula performed best across a range of lipid values in a large database of hospitalized patients. ${ }^{14}$ The correlation of our study was similar to the other studies where the correlation between calculated and direct LDL-C ranged from 0.78 to $0.93 .{ }^{10}$, 21,22

To find the actual relation between these methods BlandAltman plot was used, which showed clear relationship between both the directly measured LDL-C and the calculated LDL-C. There was a minimum negative bias between the direct measurement and measurement using most of the equations. The calculated LDL-C values using most of the equations were higher than direct measurement. This was evident in normal and borderline high TG group with the exception of Hattori equation. Similar trends of higher results with calculated LDL-C as compared to directly measured LDL-C was seen in previous studies. ${ }^{13}$, ${ }^{23-26}$ Most of these studies compared calculated LDL-C using Friedewald equation with direct LDL-C. In contrast to our finding, Vujovic et al. found significantly lower calculated LDL compared to direct LDL-C in Serbian population. ${ }^{9}$ Similar finding of underestimation of calculated LDL-C using Friedewald equation was found in a study done in Pakistan. ${ }^{27}$ This underestimation by Friedewald equation was also reported by Kamal et al. and Chen et al. ${ }^{6,22}$

Differences in the results of different studies may be attributed to diversity in population, pathologies and kits used. Measurement uncertainty that arises from three 

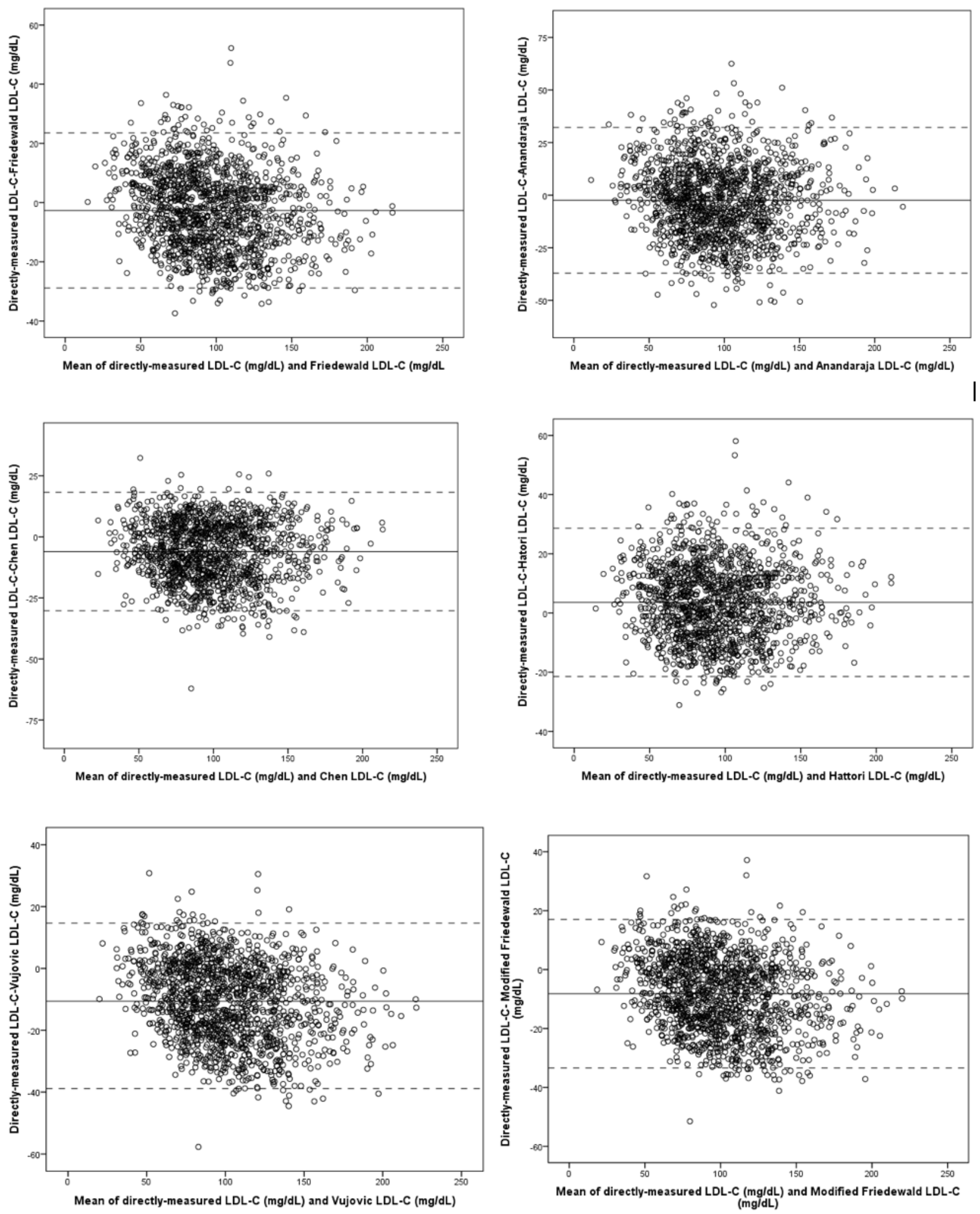

Figure 1: Bland-Altman plots of estimated formulas against directly-measured LDL-C.

independent parameters used to calculate LDL-C may have a major contribution to these differences. Arderiu and colleagues in a multicenter study reported that measurement uncertainty of direct assay was $6.9 \%$ as compared to $19.4 \%$ of calculated method and total error of calculated method was greater than the total allowable error $(\leq 12)$ for LDL-C estimation..$^{28}$

Friedewald equation has been shown to be relatively reliable and recommended by the NCEP as a routine 
method for estimation of LDL-C despite it having several well-established constraints. It cannot be applied to samples containing TG levels $>400 \mathrm{mg} / \mathrm{dL}$, to non-fasting samples and to samples of patients with dysbetalipoproteinemia (Fredrickson Type III)., ${ }^{4,29}$ Some authors have demonstrated that the formula should not be used in certain groups of patients with diabetes, liver and renal dysfunction even with TG levels $<400 \mathrm{mg} / \mathrm{dL}$. ${ }^{15,30,31}$ The results of our study showed that apart from the most commonly used Friedewald equation, Hattori equation can be used to calculate LDL-C when TG is $<200 \mathrm{mg} / \mathrm{dl}$. Unlike the Friedewald formula, the Hattori formula excludes IDL to provide a more accurate estimate of LDL-C.

The present study also had several limitations that need to be addressed. First, the beta quantification method was not used, which is considered the gold standard method for measuring LDL-C. Instead, LDL-C was measured using the enzymatic method. Second, we did not exclude participants who were taking statins or other lipid-modifying agents, which could have affected results. Other limitations of our study include the fact that racial origins were not specified and could not be considered in the analysis. However, the database is from a large hospital based population representative of the various ethnic origins of Nepal. Although patient-specific data about the disease, treatments and ethnicity was not available, our database of hospitalized patients is representative of those with diabetes, dyslipidemia and other metabolic conditions and co-morbidities.

\section{CONCLUSIONS}

Most of the LDL-C formulas correlated well with directlymeasured LDL-C. Among the six LDL-C formulas, the Friedewald equation showed the best performance for estimating LDL-C, while the Hattori equation showed a higher accuracy in people with normal and borderline high TG compared with other formulas. Since the performance of calculated methods was not uniform at different TG levels, for correct cardiac risk classification, direct homogeneous assay should be the method of choice to estimate LDL-C in routine clinical laboratories. Calculation of LDL-C based on Friedewald and Hattori equation can be a good alternative for direct measurement especially in regions with limited resources.

\section{Conflict of interest: None}

\section{REFERENCES}

1. Castelli WP, Garrison RJ, Wilson PW, Abbott RD, Kalousdian S, Kannel WB. Incidence of coronary heart disease and lipoprotein cholesterol levels: the Framingham Study. Jama. 1986;256:2835-8. Crossref

2. Expert Panel on Detection E. Executive summary of the Third Report of the National Cholesterol Education Program (NCEP) expert panel on detection, evaluation, and treatment of high blood cholesterol in adults (Adult Treatment Panel III). Jama. 2001;285:2486. Crossref

3. Türkalp I, Çil Z, Ozkazanç D. Analytical performance of a direct assay for LDL-cholesterol: a comparative assessment versus Friedewald's formula. Anadolu kardiyoloji dergisi: Anadolu Kardiyol Derg. 2005;5:13-7. Website

4. Friedewald WT, Levy RI, Fredrickson DS. Estimation of the concentration of low-density lipoprotein cholesterol in plasma, without use of the preparative ultracentrifuge. Clinical chemistry 1972;18:499-502. Crossref

5. Anandaraja S, Narang R, Godeswar R, Laksmy R, Talwar K. Lowdensity lipoprotein cholesterol estimation by a new formula in Indian population. International journal of cardiology 2005;102:117-20. Crossref

6. Chen Y, Zhang X, Pan B, Jin X, Yao H, Chen B, et al. A modified formula for calculating low-density lipoprotein cholesterol values. Lipids in Health and Dis 2010;9:52. Crossref

7. de Cordova CMM, de Cordova MM. A new accurate, simple formula for LDL-cholesterol estimation based on directly measured blood lipids from a large cohort. Annals of clinical biochemistry 2013;50:13-9. Crossref

8. Hattori Y, Suzuki M, Tsushima M, Yoshida M, Tokunaga Y, Wang Y, et al. Development of approximate formula for LDL-chol, LDL-apo B and LDL-chol/LDL-apo B as indices of hyperapobetalipoproteinemia and small dense LDL. Atherosclerosis 1998;138:289-99. Crossref

9. Vujovic A, Kotur-Stevuljevic J, Spasic S, Bujisic N, Martinovic $\mathrm{J}$, Vujovic M, et al. Evaluation of different formulas for LDL-C calculation. Lipids Health Dis 2010;9:27. Crossref

10. Martin SS, Blaha MJ, Elshazly MB, Brinton EA, Toth PP, McEvoy JW, et al. Friedewald-estimated versus directly measured low-density lipoprotein cholesterol and treatment implications. Journal of the American College of Cardiology 2013;62:732-9. Crossref

11. Scharnagl H, Nauck M, Wieland H, März W. The Friedewald formula underestimates LDL cholesterol at low concentrations. Clinical chemistry and laboratory medicine 2001;39:426-31. Crossref

12. Gupta S, Verma M, Singh K. Does LDL-C Estimation Using Anandaraja's Formula Give a Better Agreement with Direct LDL-C Estimation than the Friedewald's Formula? Indian J Clin Biochem 2012;27:127-33. Crossref

13. Gasko R. Low-density lipoprotein cholesterol estimation by the Anandaraja's formula-confirmation. Lipids in Health and Dis 2006;5:18. Crossref

14. Martins J, Olorunju SA, Murray L, Pillay TS. Comparison of equations for the calculation of LDL-cholesterol in hospitalized patients. Clinica Chimica Acta 2015;444:137-42. Crossref 
15. Rubiés-Prat J, Reverter JL, Sentí M, Pedro-Botet J, Salinas I, Lucas A, et al. Calculated low-density lipoprotein cholesterol should not be used for management of lipoprotein abnormalities in patients with diabetes mellitus. Diabetes care 1993;16:1081-6. Crossref

16. Choi S-Y, Park HE, Kim M-K, Shin CS, Cho S-H, Oh B-H. Difference between calculated and direct-measured low-density lipoprotein cholesterol in subjects with diabetes mellitus or taking lipid-lowering medications. J Clin lipidol 2012;6:114-20. Crossref

17. Puavilai W, Laoragpongse D. Is calculated LDL-C by using the new modified Friedewald equation better than the standard Friedewald equation? J J Med Assoc Thai. 2004;87:589-93. Crossref

18. Third report of the National Cholesterol Education Program (NCEP) Expert Panel on detection, evaluation, and treatment of high blood cholesterol in adults (Adult Treatment Panel III): International Medical Pub; 2002. Crossref

19. Goodman DS, Hulley SB, Clark LT, Davis C, Fuster V, LaRosa JC, et al. Report of the National Cholesterol Education Program Expert Panel on detection, evaluation, and treatment of high blood cholesterol in adults. Archives of Internal Medicine 1988;148:36-69. Crossref

20. Onyenekwu CP, Hoffmann M, Smit F, Matsha TE, Erasmus RT. Comparison of LDL-cholesterol estimate using the Friedewald formula and the newly proposed de Cordova formula with a directly measured LDL-cholesterol in a healthy South African population. Annals of clinical biochemistry 2014;51:672-9. Crossref

21. Kapoor R, Chakraborty M, Singh N. A leap above Friedewald formula for calculation of low-density lipoprotein-cholesterol. J Lab physicians 2015;7:11. Crossref

22. Kamal AHM, Hossain M, Chowdhury S, Mahmud NU. A comparison of calculated with direct measurement of low density lipoprotein cholesterol level. Journal of Chittagong Medical College Teachers' Association 2009;20:19-23. Crossref

23. Sahu S, Chawla R, Uppal B. Comparison of two methods of estimation of low density lipoprotein cholesterol, the direct versus Friedewald estimation. Indian J Clin Biochem 2005;20:54-61. Crossref
24. Ephraim RK, Acheampong E, Swaray SM, Odame Anto E, Agbodzakey H, Adoba P, et al. Developing a Modified Low-Density Lipoprotein (M-LDL-C) Friedewald's Equation as a Substitute for Direct LDL-C Measure in a Ghanaian Population: A Comparative Study. Journal of lipids 2018. Crossref

25. Boshtam M, Ramezani MA, Naderi G, Sarrafzadegan N. Is Friedewald formula a good estimation for low density lipoprotein level in Iranian population? J Res Med Sci. 2012;17:519. Crossref

26. Mora S, Rifai N, Buring JE, Ridker PM. Comparison of LDL cholesterol concentrations by Friedewald calculation and direct measurement in relation to cardiovascular events in 27331 women. Clinical chemistry 2009;55:888-94. Crossref

27. Anwar M, Khan DA, Khan FA. Comparison of Friedewald formula and modified Friedewald formula with direct homogeneous assay for low density lipoprotein cholesterol estimation. J Coll Physicians Surg Pak 2014;24:8-12. Website

28. Fuentes-Arderiu X, Braga-Fernández S, Freire-Campo L, GarcíaLario JV, García-Martín MI, Jorde-Andrés JL, et al. Comparison of measurement uncertainties in direct plasma low-density lipoprotein cholesterol method of measurement and indirect estimation according to Friedewald equation. Accreditation and quality assurance 2009; 14:179-83. Crossref

29. Nauck M, Warnick GR, Rifai N. Methods for measurement of LDL-cholesterol: a critical assessment of direct measurement by homogeneous assays versus calculation. Clinical chemistry 2002;48:236-54. Crossref

30. Bairaktari ET, Seferiadis KI, Elisaf MS. Evaluation of methods for the measurement of low-density lipoprotein cholesterol. J Cardiovasc Pharmacol 2005;10:45-54. Crossref

31. Matas C, Cabre M, La Ville A, Prats E, Joven J, Turner PR, et al. Limitations of the Friedewald formula for estimating low-density lipoprotein cholesterol in alcoholics with liver disease. Clinical chemistry. 1994;40:404-6. Crossref 